\title{
Perioperative monitoring of left ventricular contractility
}

\author{
Shoh Tatebe, MD, PhD, Michael J. Davies, MD, FRCS, Victor T. Tsang, MD, FRCS, and Martin J. Elliott, MD, FRCS, \\ London, United Kingdom
}

I nvestigations into the mechanisms underlying postoperative myocardial dysfunction, as well as investigations into modifications of its treatment, are now highly emphasized as increasing numbers of children undergo cardiac surgery during infancy. $\mathrm{We}^{1,2}$ have already found the preload recruitable stroke work index (PRSWi) to be a reliable and less invasive method to investigate myocardial contractility in clinical settings. This method has been applied during operations and has helped in assessing changes in contractility. On the basis of this experience, we aimed to develop this method for perioperative monitoring of myocardial contractility in our hospital cardiac intensive care unit (CICU). We herewith present cases in which myocardial contractility was successfully monitored up to 24 hours after cardiac surgery.

\section{Patients}

The design of this study, including the instruments used, was reviewed and approved by the Great Ormond Street Hospital for Children NHS Trust and by the Institute of Child Health Research Ethics Committee. Informed consent was obtained from patients or the parents of patients who were undergoing surgical repair for cardiac defects at Great Ormond Street Hospital for Children.

From the Cardiothoracic Unit, Great Ormond Street Hospital for Children NHS Trust, Great Ormond Street, London WC1N 3JH, United Kingdom.

This study was supported by the British Heart Foundation (BHF Project Grant No. PG/97166). One author (S.T.) was a recipient of a research fellowship of the Uehara Memorial Foundation, Tokyo, Japan

Received for publication March 2, 2001; accepted for publication April 2, 2001.

Address for reprints: Shoh Tatebe, MD, PhD, Department of Thoracic and Cardiovascular Surgery, Niigata University School of Medicine, 757 Asahimachi-Dohri 1, Niigata City, 951-8510, Japan.

J Thorac Cardiovasc Surg 2001;122:1036-8

Copyright (C) 2001 by The American Association for Thoracic Surgery

$0022-5223 / 2001 \$ 35.00+0 \quad \mathbf{1 2 / 5 4 / 1 1 6 1 9 4}$

doi: $10.1067 / \mathrm{mtc} .2001 .116194$
Because of lack of availability of the method we used, patients with single ventricle were excluded.

\section{Procedures}

All children were anesthetized in a standard manner, apart from the placement of a thermodilution-type balloon-tipped catheter in the inferior vena cava. The catheter was introduced from the femoral vein and used for vena caval occlusion during data acquisition in the CICU. A 5F balloon-tipped catheter was used in the patients whose weight was less than $10 \mathrm{~kg}$, and in those over 10 $\mathrm{kg}$, a $6 \mathrm{~F}$ catheter was chosen. All of the instruments used in this study, such as a pair of ultrasonic dimension transducers (model IMA-80, Ultrasonic dimension probe for $4 \mathrm{MHz}$; Inter Medical Co Ltd, Nagoya, Japan) and a 3.5F micromanometer-tipped catheter (Mikro-Tip, model SPR-524; Millar Instruments, Inc, Houston, Tex) were introduced via a stab skin incision of the anterior chest, which allows transcutaneous removal in the CICU. As described previously, ${ }^{1}$ a pair of ultrasonic dimension transducers were attached across the anteroposterior minor axis diameter of the left ventricle (LV), and a micromanometer-tipped catheter was introduced from the roof of the left atrium to the midportion of the LV. During data acquisition in the CICU, the preload was altered by vena caval occlusion by inflating the balloon-tipped catheter with the tip placed just below the inferior vena cava-right atrial junction. Data obtained from these instruments were analyzed by a personal computer-based data acquisition system (DMDAS; Medical Research Technology, Reston, Va) and its software. Data were basically recorded at 3 points during the operation (before and after cardiopulmonary bypass and after completion of modified ultrafiltration [MUF]) and at 6 points in the CICU (1, 2, 4, 8, 12 , and 24 hours after the operation). The relationship between end-diastolic length and stroke work index was generated from the data of each, and the linear slope $(\mathrm{Mw})$ of that relationship was considered as a parameter representing myocardial contractility. All instruments were removed transcutaneously 24 hours after the operation or before removal of the endotracheal tube, whichever was earlier. The ultrasonic dimension transducers and micromanometer-tipped catheter were removed by simply pulling them 




Figure 1. A representative change of the slope $(M w)$ of preload recruitable stroke work index in a 10-month-old boy with tetralogy of Fallot. CPB, Cardiopulmonary bypass; MUF, modified ultrafiltration; DOP, dopamine; GTN, glycerine trinitrate.

\section{TABLE 1. Summary of the patients}

\begin{tabular}{lllll}
\hline Patient & Age & Sex & Diagnosis & Operation \\
\hline 1 & $3 \mathrm{~m}$ & $\mathrm{~F}$ & Ventricular septal defect & Closure \\
2 & $8 \mathrm{~m}$ & $\mathrm{~F}$ & Ventricular septal defect & Closure \\
3 & $9 \mathrm{~m}$ & $\mathrm{~F}$ & Tetralogy of Fallot & Total repair \\
4 & $10 \mathrm{~m}$ & $\mathrm{~F}$ & Tetralogy of Fallot & Total repair \\
5 & $10 \mathrm{~m}$ & $\mathrm{M}$ & Tetralogy of Fallot & Total repair \\
6 & $1 \mathrm{y}$ & $\mathrm{M}$ & Ventricular septal defect & Closure \\
7 & $1 \mathrm{y}$ & $\mathrm{M}$ & Tetralogy of Fallot & Total repair \\
8 & $1 \mathrm{y} 3 \mathrm{~m}$ & Ventricular septal defect & Closure \\
9 & $10 \mathrm{y}$ & Aortic regurgitation & Ross procedure \\
\hline
\end{tabular}

out, in a fashion similar to the removal of a temporary pacemaker wire. A follow-up echocardiogram was performed several hours after the removal.

\section{Results}

Table 1 depicts the 9 patients who were enrolled in this study. They included 4 boys and 5 girls, and they ranged in age from 3 months to 10 years. Diagnoses were ventricular septal defect in 4 , tetralogy of Fallot in 4, and aortic regurgitation in 1 patient. The patient with aortic regurgitation underwent a Ross procedure.

Figure 1 shows a change of $\mathrm{Mw}$ in the relationship between end-diastolic length and stroke work index obtained from the patient with tetralogy of Fallot. The myocardial contractility repre- sented by Mw increased after MUF during the operation. After the patient was transferred to the CICU, Mw remained at its post-MUF level and culminated 2 hours after the operation. Then Mw gradually decreased to the level present just before the commencement of cardiopulmonary bypass, which was considered relatively impaired contractility. The heart had recovered 24 hours after the operation as a result of an increased dosage of inotropic agents. The changes in myocardial contractility observed throughout the course corresponded to the clinical picture in the CICU.

After completion of data acquisition, the ultrasonic dimension transducers and micromanometer-tipped catheter were smoothly removed transcutaneously. No complications or consequences have been related to this study. 


\section{Discussion}

We have demonstrated the feasibility of an ultrasonometric method to perioperatively monitor myocardial contractility, and we have found it suitable as a tool in the clinical settings of pediatric cardiac surgery.

The concept of PRSWi was developed by Glower and associates $^{3}$ as a load-insensitive index of left ventricular systolic function. ${ }^{3}$ Several studies followed and confirmed this pressurevolume/length relationship to be a highly reproducible linear index of left ventricular systolic function, not only in the adult human heart but also in the neonatal heart. Our previous study regarding $\mathrm{PRSWi}^{2}$ confirmed that it was valid even in the single-dimension method, and $\mathrm{Mw}$ was tolerated well in the clinical settings. ${ }^{1}$ As shown in Figure 1, Mw was properly monitored in this study.

Apart from the method we used, several methods of measuring PRSWi are known. A conductance catheter is now considered a useful and reliable method for assessing the geometry of the heart. Chaturvedi and colleagues ${ }^{4}$ successfully monitored myocardial contractility during surgery using a conductance and micromanometer-tipped catheter on patients undergoing surgical repair of the heart. Although it may assess ventricular geometry more accurately than ours, this method may have a disadvantage in postoperative monitoring, because it is not practical to leave the conductance catheter in the center of the LV. In most cases the catheter is currently introduced from the apex of the LV or from a branch artery through the ascending aorta; there are no appropriate methods available to remove the conductance catheter in the postoperative period. In addition to the issue of feasibility, a criticism arose in regard to the potential risk contingent on the procedure used to introduce the catheter from the apex of the LV: namely, this procedure may have resulted in transmural scarring, which may have increased the potential risk of arrhythmia. ${ }^{5}$ The method described in the present study, including the instruments it employs, cannot carry such a risk or increase the risk beyond that entailed in the usual surgical procedures. This is because a micromanometertipped catheter was introduced from the roof of the left atrium, which was equivalent to the routine insertion of a left atrial pressure line in cardiac surgery. The ultrasonic dimension transducers were attached and removed in the same manner as that of the temporary pacemaker wire. And the balloon-tipped catheter in the inferior vena cava is also used in the CICU as an indwelling catheter in the central vein.

In conclusion, we report an ultrasonometric method that is useful for perioperative assessment of myocardial contractility. This method is safe and well tolerated clinically as well as ethically, and it has the potential to be used widely in the clinical settings of pediatric cardiac surgery.

\section{References}

1. Davies MJ, Nguyen K, Gaynor JW, Elliott MJ, de Leval MR Modified ultrafiltration improves left ventricular systolic function in infants after cardiopulmonary bypass. $J$ Thorac Cardiovasc Surg. 1998;115:361-70.

2. Davies MJ, Quarterman RL, Tsui SSL, Jacobs MT, Davis JW, Elliott MJ, et al. Comparison of three indexes of contractility in the neonatal left ventricle. Cardiovasc Eng. 1997;2:180-90.

3. Glower DD, Spratt JA, Snow ND, Kabas JS, Davis JW, Olsen CO, et al. Linearity of the Frank-Starling relationship in the intact heart: the concept of preload recruitable stroke work. Circulation. 1985;71:9941009.

4. Chaturvedi RR, Lincoln C, Gothard JWW, Scallan MH, White PA, Redington AN, et al. Left ventricular dysfunction after open repair of simple congenital heart defects in infants and children: quantitation with the use of a conductance catheter immediately after bypass. $J$ Thorac Cardiovasc Surg. 1998;115:77-83.

5. Colan SD, del Nido PJ. Editorial: Left ventricular dysfunction after open repair of simple congenital heart defects in infants and children. J Thorac Cardiovasc Surg. 1998;115:74-6. 